\title{
Analysis of Semi-solid Processing for Metal Matrix Composite Synthesis Using Factorial Design
}

\author{
Kratus Ranieri $^{\mathrm{a} *}$, Carlos Kiyan ${ }^{\mathrm{a}}$,Antonio Fernando Branco Costa ${ }^{\mathrm{b}}$, Alexandre Zirpoli Simões ${ }^{\mathrm{a}}$ \\ ${ }^{a}$ Department of Materials and Technology, São Paulo State University - UNESP, \\ Av. Dr. Ariberto Pereira da Cunha,333, CEP 12516-410, Guaratinguetá, SP, Brazil \\ ${ }^{\mathrm{b}}$ Production Department, São Paulo State University - UNESP, Av. Dr. Ariberto Pereira da Cunha, 333, \\ CEP 12516-410, Guaratinguetá, SP, Brazil
}

Received: September 4, 2011; Revised: November 17, 2011

\begin{abstract}
The main goal in this work is to conduct a quantitative analysis of the mechanical stir casting process for obtaining particulate metal matrix composites. A combined route of stirring at semi-solid state followed by stirring at liquid state is proposed. A fractional factorial design was developed to investigate the influence and interactions of factors as: time, rotation, initial fraction and particle size, on the incorporated fraction. The best incorporations were obtained with all factors at high levels, as well as that very long stirring periods have no strong influence being particle size and rotation the most important factors on the incorporated fraction. Particle wetting occurs during stirring at semisolid state, highlighting the importance of the interactions between particles and the alloy globularized phase. The role of the alloying element $\mathrm{Mg}$ as a wettability-promoting agent is discussed. The shear forces resulting from the stirring system is emphasized and understood as the effect of rotation itself added to the propeller blade geometry.
\end{abstract}

Keywords: stir casting, semi solid processing, metal matrix composites

\section{Introduction}

In the last years, the fabrication of particulate metal matrix composites (MMCp) by casting processes has received attention due its commercial importance. Methods using thixocasting and rheocasting are among the simplest and cheapest ones for MMCp fabrication, especially the mechanical stir casting. In general, these process routes can be grouped by the matrix physical state, in other words: i) processes with the matrix in the liquid state; ii) processes with the matrix in the semi-solid state; and iii) combinations of routes (i) and (ii).

Mechanical stir casting involves three mechanisms: i) particles must be wetted by the metal; ii) dispersion must be achieved; and iii) composite pouring and solidification must follow. Therefore, the wetting condition is necessary but not sufficient for composite synthesis.

The addition of alloying elements is a well-known technique for improving ceramic particle wettability, especially $\mathrm{Mg}$ in aluminium alloys. $\mathrm{Mg}$ reacts with the oxygen present on the particle surfaces, thereby thinning the gas layer, improving wettability and decreasing the tendency to form agglomerates. Levi ${ }^{1}$, in a study conducted with Al/ $\mathrm{Mg}$ alloy reinforced with alumina fibres, demonstrated that the presence of $\mathrm{Mg}$ is essential for fibre wetting. Ghost ${ }^{2}$ and Quingley ${ }^{3}$ confirmed the formation of $\mathrm{MgAl}_{2} \mathrm{O}_{4}$ spinel in alloys with $\mathrm{Mg}$ content below $4 \%$. On the other hand, $\mathrm{Pai}^{4}$ and $\mathrm{Mcleod}^{5}$ also observed the formation of $\mathrm{MgO}$ as well as a thin layer of $\mathrm{Al}_{2} \mathrm{O}_{3}$, depending on the $\mathrm{Mg}$ content.

\footnotetext{
*e-mail: kratusranieri@ig.com.br
}

In order to obtain a material with optimal mechanical properties, characteristics such as reinforcement distribution homogeneity inside the matrix, interface resistance, adherence between reinforcement and matrix, matrix porosity, volume fraction and size of the incorporated reinforcement should be considered. Reinforcement fraction is a basic composite requirement and has an essential role in its mechanical properties.

The wettability and therefore the incorporated fraction is significantly affected by numerous factors such as: stirring time, rotation, propeller blade position and geometry, particle morphology and particle size, particle superficial treatments, matrix alloy composition, wettability and reactivity of the metal alloy - ceramic particle system. Naher et al. ${ }^{6}$, using $\mathrm{SiC}$ as reinforcement, showed that rotation, viscosity and stem-crucible geometry have great influences on particle incorporation and dispersion uniformity. Naher et al. ${ }^{7}$ obtained $\mathrm{SiC}$ incorporation in semi-solid processing without the use of recovering techniques. However, the same results were not obtained with stirring at a fully liquid state.

The alternative to the liquid-state processing is the semi-solid state processing, which favours wettability and dispersion uniformity in general. The partially solidified alloy under stirring has a primary solidified phase present in the remaining liquid in the form of spheroidized particles or globules. When ceramic particles are added to the metallic slurry, its complexity in the formation of dispersion increases, due to the presence of two solid phases with different particle size and chemical compositions. The 
ceramic particles produce opposite effects: an increase in slurry viscosity with the increase in the solid fraction and a decrease in slurry viscosity by the decrease in agglomerate formation. These are kinetic phenomena, and therefore the metallic slurry presents a thixotropic behaviour, i.e., it is time dependent.

In this work, a combined processing route is presented. This route comprehends semi-solid state stirring followed by liquid state stirring to obtain enough fluidity for pouring. The matrix material is the AA 356 alloy, widely used to cast components for automotive industries, especially to produce engine block ${ }^{8}$. The most common reinforcing ceramics for Al-Si alloys are $\mathrm{SiC}$ and $\mathrm{Al}_{2} \mathrm{O}_{3}{ }^{8}$. Because the specific scope of this work was the investigation of the relationship among process factors with the incorporated fraction, it was convenient to choose $\alpha$-alumina as the reinforcement since it is a material that shows difficulties of incorporation due to its low reactivity with aluminium alloy.

Studies that approach the relationship among process factors directly to the incorporated fraction in the synthesis of MMCp by mechanical stir casting at the semi-solid state are rare, and there is little information about how factors interact. If a experiment is affected by two or more factors, the synergistic effect is the difference between the total effect when the factors play a role simultaneously and the total effect when the factors act separately in sequence. Thus, from an experimental point of view, a quantitative analysis, using tools from statistics, of the MMCp synthesis by mechanical stir casting can be a powerful support for a better understanding of the process and to develop a rational design of this system.

\section{Materials and Methods}

\subsection{Material}

For the matrix material the commercial AA 356 alloy supplied by NOVELIS - Poços de Caldas/MG was used in ingots of $25 \mathrm{~kg}$. The ingots were sawn in cubes of approximately $15 \times 15 \mathrm{~mm}$ and separated in portions of $350 \mathrm{~g}$ for each processing operation. The alloy composition, determined by atomic absorption spectroscopy (\%wg), is the following: $7.0 \mathrm{Si} / 0.25 \mathrm{Cu} / 0.32 \mathrm{Mg} / 0.35 \mathrm{Mn} / 0.60 \mathrm{Fe} / 0.35$ $\mathrm{Zn}$. The AA 356 alloy is a triphasic Al-7Si-0.3Mg alloy, and it has a liquidus temperature of $615^{\circ} \mathrm{C}$ and a solidus temperature of $534^{\circ} \mathrm{C}$ in out-of-balance cooling conditions determined by Jeng and Chen ${ }^{9}$ by means of differential thermal analysis. These temperatures were choosen as reference in order to obtain the semi-solid slurry.

For the reinforcement, calcined alumina (known commercially as milled alpha alumina) was used. The alumina was supplied by NOVELIS - Poços de Caldas/MG and classified by sieving. In all processing steps, the particles were thermal treated at $1000{ }^{\circ} \mathrm{C}$ for 1 hours.

\subsection{Composite processing}

The composites were processed in a device developed and tested in an earlier work by Ranieri and Kiyan ${ }^{10}$. The propeller blades are of axial type with two opposite blades and a graphite crucible. The procedure was the following:
1) total alloy melting at a temperature of $650^{\circ} \mathrm{C} ; 2$ ) injection of an argon shield and cleaning of the superficial slag with a spoon; 3) stirring start at a temperature higher than the liquidus temperature; 4) continuation of stirring until cooling at a temperature between the liquidus and solidus (approximately $580-590{ }^{\circ} \mathrm{C}$ ) and introduction of the preheated particles (at $1000{ }^{\circ} \mathrm{C}$ ) through the vortex; 5) stirring of the metallic slurry with particles for a pre-established time; 6) end of stirring followed by reheating at $700{ }^{\circ} \mathrm{C}$; 7) stirring for 60 seconds followed by pouring in polished steel ingots measuring $38 \times 38 \mathrm{~mm}$ in the transversal section. A typical processing Temperature $\times$ Time curve is presented in Figure 1. Four ingots were fabricated for preliminary experiments and eight ingots for the fractional factorial experiment.

The temperature of the furnace was manually controlled by observing the temperature variation besides with time along processing. These data were collected from a thermocouple inserted through a hole in the crucible wall. The measurements were registered by a data acquisition device and checked directly in the liquid metal. Yielding variations of $\pm 3{ }^{\circ} \mathrm{C}$ during cooling and $\pm 6{ }^{\circ} \mathrm{C}$ at heating were considered insignificant.

\subsection{Estimation of the incorporated volume fraction}

To obtain the estimations of the incorporated volume fraction in each processing operation, the image analysis and processing associated with a specific method of statistic sampling were used. The development of the method, its mathematic treatment and its discussion are presented in the authors' previous work ${ }^{11}$.

The ingots were transversely cut in the low, middle and high sections. Each resulting section, measuring $38 \times 38 \mathrm{~mm}$, was prepared entirely without mounting. The metallographic procedure was as follows: grinding using 220, 320, 400, 600 and 1200 grit abrasive paper with water as a lubricant; polishing with a $6 \mu \mathrm{m}$ alumina emulsion; finishing with an aqueous suspension of colloidal silica; and an unetching condition.

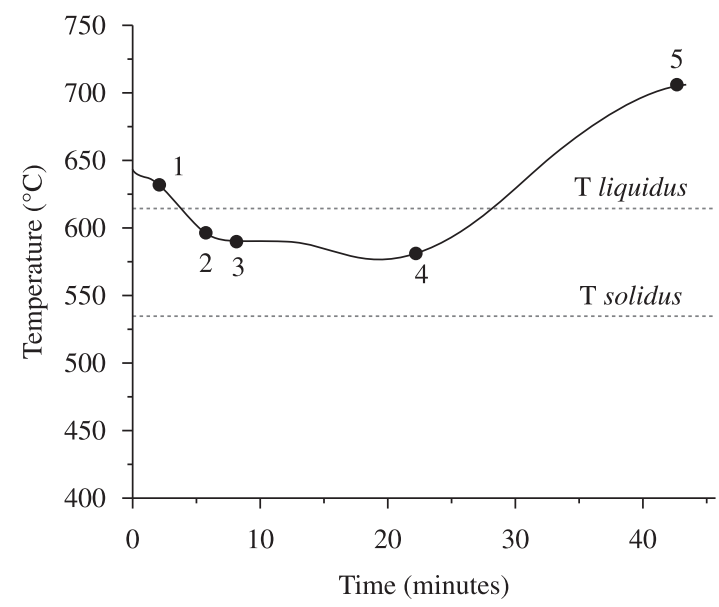

Figure 1. Typical temperature $\times$ time process. 1) Starting of stirring; 2) introduction of the pre-heated particles; 3) end of particle addition; 4) conclusion of stirring followed by reheating; 5) pouring. 
The images were acquired by using polarized light illumination in a Diagnostic Instruments Spot Insight QE Color camera and a Nikon - Epiphot 200 optical microscope. All images were taken at a magnification of 100X. For the image processing and analysis, the Image $\mathrm{J}$ free software ${ }^{12}$ was used.

For each section, 75 stratified images were collected leading to 225 images per ingot and 1800 measurements for all factorial experiment. The estimation of the incorporated fraction was done by the mean estimation of three sections. The standard error accepted was $0.5 \%$. The data processing was performed based on the procedures and terminology indicated by Montgomery ${ }^{13}$ and was developed by the authors using an Excel spread sheet.

\subsection{Factorial design}

A series of preliminary experiments was conducted to identify the study factors. The conclusions of these experiments are: 1) stirring only in the liquid state is not successful for alumina retention; 2) semi-solid state processing can produce total incorporation of particles; 3 ) little or no incorporation is accomplished with particles smaller than $45 \mu \mathrm{m}$; 4) particle retention larger than $45 \mu \mathrm{m}$ is easily obtained; and 5) apparently stirring time appears to have very little influence on particle incorporation.

Based on these indications, four factors were chosen for the conduction of a $2^{4-1}$ fractional factorial experiment. In view of the difficulty of incorporation, the liquid state processing was discarded as an option. The study range is set at $45-100 \mu \mathrm{m}$. The maximum rotation limit was $600 \mathrm{rpm}$. The initial fraction represents the initial state of the system. The factors and their levels are listed in Table 1.

Other factors, such as matrix and reinforcement composition, crucible and propeller blade geometry, reinforcement treatment and mould material, were kept constant.

\section{Results and Discussion}

\subsection{Data analysis and determination of volume fraction}

The initial data analysis found 118 outliers. Outliers are always a source of inconvenience in any measurement process. Their presence changes the data group mean and variance; however, they cannot be discarded without a strong reason. A preliminary investigation of these points showed that there were no failures during data registration or in volume fraction calculation. The detailed inspection of each image, evidenced failures in image acquisition, such as out of focus or cavity images due to solidification shrinkage, that could not be completely eliminated by the image processing. The corrupted images (Figure 2) were discarded and replaced by new measurements. Figure 3 shows a typical image used for volume fraction measurements. By this criterion, 43 outliers were corrected and the other remaining 75 outliers were kept and considered as associated to the great heterogeneity of particle distribution. The new data recording with outlier purge was the one used for estimating the volume fractions and constructing the factorial.
Table 1. Experimental conditions of the selected factors for the factorial design.

\begin{tabular}{llcc}
\hline & \multicolumn{1}{c}{ Factor } & Slow level $(-)$ & High level $(+)$ \\
\hline A & Particle size $(\mu \mathrm{m})$ & $45-53$ & $90-106$ \\
B & Rotation $(\mathrm{rpm})$ & 300 & 600 \\
C & Stir time $(\mathrm{s})$ & 600 & 1800 \\
$\mathrm{D}$ & Initial fraction $(\%)$ & 5 & 10 \\
\hline
\end{tabular}

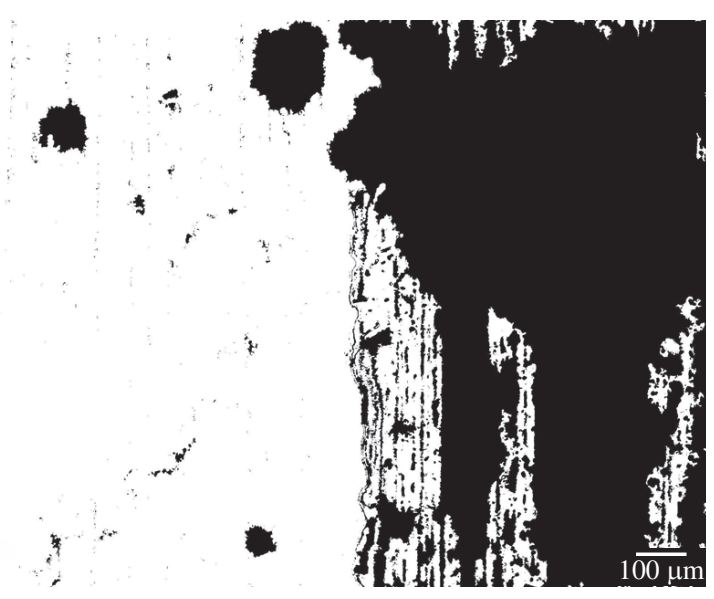

Figure 2. Corrupted image.

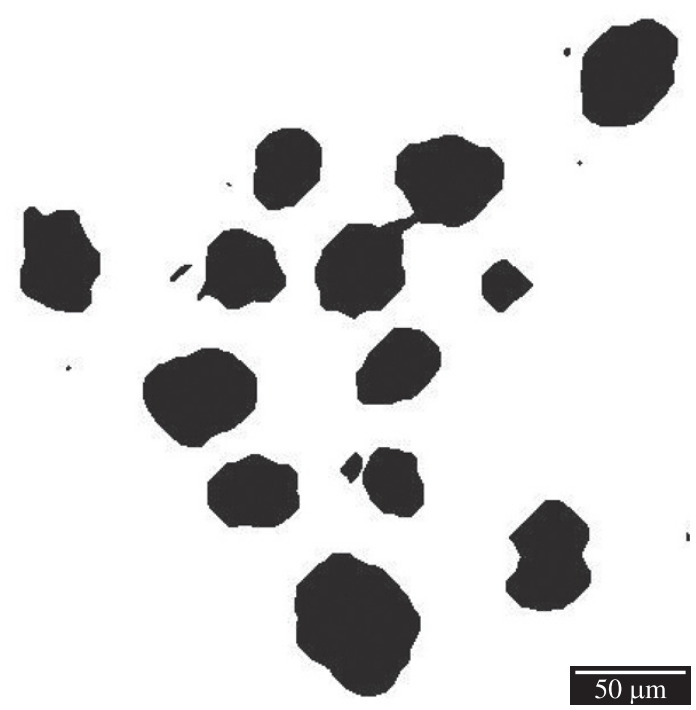

Figure 3. Typical image used for volume fraction measurements.

The estimation of the mean volume fraction and standard error in each of the three inspected sections of each ingot are summarized in Table 2. The last column, called "global mean", refers to the arithmetic mean of the estimation of the three inspected sections of the ingot.

The examination of the mean values in Table 2 reveals that incorporation is total in ingots 2 and 8 , partial in ingots 3, 4, 6 and 7, and near $0.5 \%$ in ingots 1 and 5. Those ingots with estimations that are very close to the accepted 
Table 2. Estimated mean volumetric fraction $\overline{\mathrm{f}}_{\mathrm{v}}(\%)$. (SE: Standard error).

\begin{tabular}{cccccc}
\hline Ingot & & $\begin{array}{c}\text { Low } \\
\text { section }\end{array}$ & $\begin{array}{c}\text { Middle } \\
\text { section }\end{array}$ & $\begin{array}{c}\text { High } \\
\text { section }\end{array}$ & $\begin{array}{c}\text { Global } \\
\text { mean }\end{array}$ \\
\hline \multirow{2}{*}{1} & $\mathrm{f}_{\mathrm{v}}$ & 0.40 & 0.82 & 0.76 & 0.66 \\
& $\mathrm{SE}$ & 0.09 & 0.14 & 0.13 & 0.12 \\
2 & $\mathrm{f}_{\mathrm{v}}$ & 2.99 & 6.77 & 5.46 & 5.07 \\
& $\mathrm{SE}$ & 0.40 & $\mathbf{0 . 6 0}$ & 0.47 & 0.49 \\
3 & $\mathrm{f}_{\mathrm{v}}$ & 0.96 & 2.56 & 4.43 & 2.65 \\
& $\mathrm{SE}$ & 0.15 & 0.34 & $\mathbf{0 . 5 5}$ & 0.35 \\
\multirow{2}{*}{4} & $\mathrm{f}_{\mathrm{v}}$ & 1.43 & 3.28 & 3.25 & 2.66 \\
& $\mathrm{SE}$ & 0.21 & 0.38 & 0.34 & 0.31 \\
5 & $\mathrm{f}_{\mathrm{v}}$ & 0.28 & 0.51 & 0.54 & 0.44 \\
& $\mathrm{SE}$ & 0.06 & 0.13 & 0.13 & 0.11 \\
6 & $\mathrm{f}_{\mathrm{v}}$ & 1.49 & 2.92 & 1.34 & 1.92 \\
& $\mathrm{SE}$ & 0.27 & 0.29 & 0.23 & 0.27 \\
7 & $\mathrm{f}_{\mathrm{v}}$ & 1.70 & 2.88 & 2.62 & 2.40 \\
& $\mathrm{SE}$ & 0.19 & 0.29 & 0.24 & 0.24 \\
\multirow{2}{*}{8} & $\mathrm{f}_{\mathrm{v}}$ & 6.34 & 8.15 & 8.07 & 7.52 \\
& $\mathrm{SE}$ & $\mathbf{0 . 5 8}$ & $\mathbf{0 . 6 4}$ & $\mathbf{0 . 6 7}$ & 0.63 \\
\hline
\end{tabular}

error $(0.5 \%)$ can be considered to have no incorporation. In all ingots the estimated volume fraction is smaller in the low section than in the middle and high ones, and in ingot 2 this difference is bigger. Additionally, the middle sections present estimated values that are higher in all ingots, except in numbers 3 and 4, where they can be considered the same.

All standard errors (SE) are within the initially accepted value of $0.5 \%$, except ingots 2 -mid, 3-high, 8-low, 8-mid and 8-high (marked in boldface). The reason for this abnormality could be explained by the variability among these measurement groups, which is a consequence of the great heterogeneity of particle distribution. Although these errors are out of the initially accepted range of $0.5 \%$, their low frequency of occurrence ( 5 in 24 estimations), along with the fact that more than half of the outliers were kept, led to the conclusion that the discrepancy is not enough to bring the measurement method into question.

In order to check the estimations, $95 \%$ confidence intervals $(\mathrm{CI})$ were constructed for the incorporated volume fraction mean and compared to the added volume fraction as shown in Table 3. The CIs were constructed based on the values of the mean volume fraction (global mean) and mean standard error of the last column in Table 2.

During the composite processing, a certain quantity of aluminum was discarded and removed from the slag before processing, as well as from the waste left at the bottom of the crucible after pouring. These losses modify the initial mass of metal, thereby changing the effective alumina fraction. An adjustment of the added fraction becomes necessary, and for this purpose each ingot was weighed after processing. Based on the specific alloy and alumina mass ratio, a realistic approximation could be performed, as indicated in the last column of Table 3 - "actual added volume fraction".
Table 3. Confidence interval for estimated volumetric fraction.

\begin{tabular}{ccccc}
\hline Ingot & $\overline{\mathbf{f}}_{\mathrm{v}}^{\text {ingot }}$ \%) & $\overline{\mathbf{S E}}_{\text {ingot }}$ & $\mathbf{9 5 \%} \mathbf{C I} *$ & $\begin{array}{c}\text { Actual added } \\
\text { volume } \\
\text { fraction (\%) }\end{array}$ \\
\hline 1 & 0.66 & 0.12 & $0.42<\mathrm{f}_{\mathrm{v}}<0.90$ & 4.3 \\
2 & 5.07 & 0.49 & $4.11<\mathrm{f}_{\mathrm{v}}<5.31$ & 4.3 \\
3 & 2.65 & 0.35 & $1.96<\mathrm{f}_{\mathrm{v}}<2.89$ & 4.2 \\
4 & 2.66 & 0.31 & $2.05<\mathrm{f}_{\mathrm{v}}<2.90$ & 4.3 \\
5 & 0.44 & 0.11 & $0.22<\mathrm{f}_{\mathrm{v}}<0.68$ & 8.5 \\
6 & 1.92 & 0.27 & $1.39<\mathrm{f}_{\mathrm{v}}<2.16$ & 8.5 \\
7 & 2.40 & 0.24 & $1.93<\mathrm{f}_{\mathrm{v}}<2.64$ & 8.4 \\
8 & 7.52 & 0.63 & $6.29<\mathrm{f}_{\mathrm{v}}<7.76$ & 7.7 \\
\hline$* \overline{\mathrm{f}}_{\mathrm{v}}$ ingot $-\overline{\mathrm{SE}} \times 1.96<\mathrm{fv}_{\mathrm{f}}<\overline{\mathrm{f}}_{\mathrm{v}}$ ingot $+\overline{\mathrm{SE}} \times 1.96$
\end{tabular}

\subsection{Fractional factorial experiment}

The response variables are therefore the volume fractions calculated in Table 2 in the "global mean" column. Table 4 presents, as usual, the design matrix with the processing conditions of the eight ingots included in the "measured response" column.

Table 5 presents the processed data where the "percent contribution" column indicates the participation ratio of each factor and their interactions. The Pareto chart of Figure 4 better shows the results, and it is easy to see that time (factor C), in the order of magnitude adopted in this study, has very little participation.

In fractionated factorial designs, the $\mathrm{AD}$ and $\mathrm{BC}$ interactions are calculated together, denominated as $\mathrm{AD}+\mathrm{BC}$ and referred to as confounding. If factors $\mathrm{A}, \mathrm{B}$ and $\mathrm{D}$ are the ones that exert greater influence and factor $\mathrm{C}$ 's contribution is very little, it is possible to conclude that the $\mathrm{AD}+\mathrm{BC}$ confounding has an insignificant $\mathrm{BC}$ interaction and greater weight due to the $\mathrm{AD}$ contribution. The same reason leads to the conclusion that the $\mathrm{AB}$ interaction is more meaningful than $\mathrm{CD}$ in the $\mathrm{AB}+\mathrm{CD}$ interaction, and $\mathrm{BD}$ is more meaningful than $\mathrm{AC}$ in the $\mathrm{AC}+\mathrm{BD}$ interaction. The interactions that involve factor $\mathrm{C}$ are marked as indicated in the Pareto chart.

The most important effects are due to factors A, B, D and the AD interaction. It is possible to establish a relevance hierarchy of factors and interactions. Particle size (A) is the factor with the greatest percent effect, highlighting the importance of the role of system wettability. The added fraction (D) has a great influence and interacts strongly with particle size (as AD). These two associated factors represent the total surface of the solid to be wetted. Rotation (B) comes next. It is the energy supplied to the system, and it is related to wettability. Finally, there is the AC + BD interaction with a small but suggestive participation, as is discussed next.

Since factor C (time) is irrelevant, it is discarded, making the transformation of a $2^{4-1}$ fractional factorial into a $2^{3}$ full factorial possible, with the three factors A, B and D. The Figure 5 cube diagram is constructed this way.

The observation in Figure 5 makes it clear that the best incorporation $(7.52 \%)$ is obtained with all factors at high levels, and the worst incorporation rate $(0.66 \%)$ occurs with all factors at low levels. 
Table 4. Experimental design matrix for a $2^{4-1}$ fractional factorial design and the estimated volumetric fraction.

\begin{tabular}{|c|c|c|c|c|c|c|}
\hline \multirow[t]{2}{*}{ Ingot } & \multicolumn{4}{|c|}{ Factor } & \multirow[t]{2}{*}{ Coded factors } & \multirow{2}{*}{$\begin{array}{c}\text { Estimated } \\
\text { volumetric } \\
\text { fraction } \overline{\mathbf{f}}_{\mathbf{v}}(\%)\end{array}$} \\
\hline & $\begin{array}{c}\text { Particle size } \\
\text { A }\end{array}$ & $\begin{array}{c}\text { Rotation } \\
\text { B }\end{array}$ & $\underset{\text { C }}{\text { Time }}$ & $\begin{array}{c}\text { Initial fraction } \\
\text { D }\end{array}$ & & \\
\hline 1 & - & - & - & - & (1) & 0.66 \\
\hline 2 & + & + & - & - & $a b$ & 5.07 \\
\hline 3 & + & - & + & - & $a c$ & 2.65 \\
\hline 4 & - & + & + & - & $b c$ & 2.66 \\
\hline 5 & + & - & - & + & $a d$ & 0.44 \\
\hline 6 & - & + & - & + & $b d$ & 1.92 \\
\hline 7 & - & - & + & + & $c d$ & 2.40 \\
\hline 8 & + & + & + & + & $a b c d$ & 7.52 \\
\hline
\end{tabular}

Table 5. Estimated contribution of volumetric fraction $\left(\mathrm{f}_{\mathrm{v}}\right)$.

\begin{tabular}{|c|c|c|c|c|}
\hline Factor & Structure & Estimated effect & Sum of squares & Contribution (\%) \\
\hline A (particle size) & $\mathrm{A}+\mathrm{BCD}$ & 2.75 & 15.15 & 39.43 \\
\hline B (rotation) & $\mathrm{B}+\mathrm{ACD}$ & 1.78 & 6.36 & 16.54 \\
\hline $\mathrm{C}$ (time) & $\mathrm{C}+\mathrm{ABD}$ & 0.31 & 0.19 & 0.51 \\
\hline$D\left(\right.$ inital $\left.f_{v}\right)$ & $\mathrm{D}+\mathrm{ABC}$ & 2.01 & 8.09 & 21.05 \\
\hline $\mathrm{AB}$ & $\mathrm{AB}+\mathrm{CD}$ & 0.19 & 0.07 & 0.18 \\
\hline $\mathrm{AC}$ & $\mathrm{AC}+\mathrm{BD}$ & 0.54 & 0.59 & 1.53 \\
\hline $\mathrm{BC}$ & $\mathrm{AD}+\mathrm{BC}$ & 2.00 & 7.98 & 20.75 \\
\hline
\end{tabular}

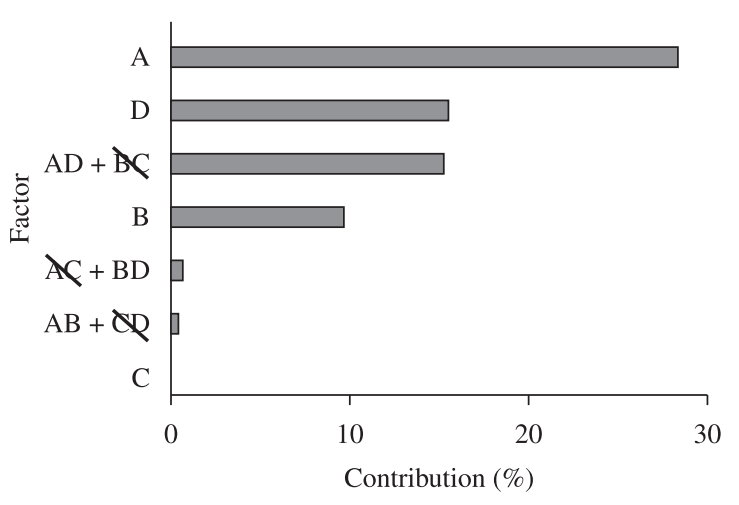

Figure 4. Pareto chart of the main effects and its interactions.

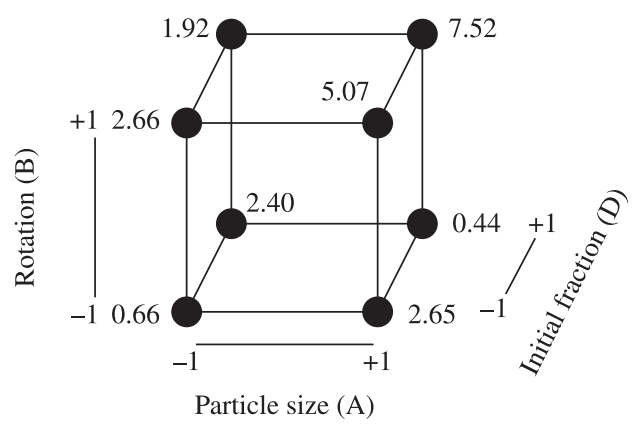

Figure 5. Cube diagram of the $2^{3}$ factorial experimental design. The values at the corners of the cube are the estimated volumetric fraction at the eight experimental conditions.

Rotation (B) has an important contribution as a separate factor, and it interacts, though weakly, with particle size (as AB) and initial fraction (as BD). When at a high level, it has a pronounced effect in all situations, although when particle size is low and initial fraction is high an inversion of effect happens; in other words, as the rotation increases, the incorporated fraction decreases (it goes from 2.40 to 1.92). This inversion indicates the interaction among factors. Assuming that the difference between 2.40 and 1.92 is in the measurement variability, it is reasonable to conclude that the values are the same and that rotation does not exert influence in this processing range. A plausible interpretation is that the increase of added fraction associated with fine particles increases the tendency to form agglomerates, and this is not sufficiently counterbalanced by rotation. When added fraction decreases, the agglomeration tendency also decreases and rotation once again has an outstanding effect, changing 0.66 to 2.66 .

The inverted behaviour is also observed in relation to rotation and initial fraction, evidence of their interaction. With rotation at a low level, thin particles added in greater quantity cause the incorporated fraction to increase by about 4 times (from 0.66 to 2.40). However, the behaviour is opposite with particle size at a high level (changing from 2.65 to 0.44 ) because the rotation is not enough to attenuate the action of gravity. Although the presence of globularized primary phase prevents decantation of non-metallic particles in general, this result shows that this is not always true, highlighting the importance of the propeller blade geometry.

As demonstrated previously by Iligbusi ${ }^{14}$, the reduction of rotation and particle size makes incorporation more difficult due the changes in the total interfacial energy. In 
addition to this, the results found here also show that there is a significant role due to the interaction among those factors, which indeed represents the abrasion or friction among the particles in the semi-solid slurry. The factorial design helped to experimentally demonstrate the existence of that interaction.

What is inferred from the previous analysis is that the metal pasty condition, rich in the solidified $\alpha$ aluminum, contributes to the formation of uniform slurry. In this stirring condition, three types of fundamental interactions occur: friction between the solidified Al- $\alpha$ phase and the ceramic particles; friction among the particles themselves; and friction between the particles and the remaining liquid, whose chemical composition is enriched by its alloying elements, especially Mg. This last interaction increases the number of energetically favourable collisions, favouring chemical reactions on the particle surfaces. In the stirring temperature range at the semi-solid state, the solid fraction determined by the Scheil equation is between 0.4 and 0.5 ; this means that the content of $\mathrm{Mg}$ present in the liquid phase is about $0.6 \%$ in weight, i.e., double the alloy nominal composition, and it can reach higher values on the particle surfaces. Therefore, the increase of alloying element concentration associated with the raise of energetically favourable collisions, when reaching a certain level, favours the chemical reaction that promotes wettability.

In the preliminary experiment, it was found that processing in a totally liquid state does not produce incorporation and that favourable results can only be obtained by processing the matrix in the semi-solid state. It is expected that, at higher temperatures and with the matrix in the liquid state, the number and frequency of collisions are greater and the reaction is more intense, improving particle wetting. Nevertheless, the result found does not confirm this hypothesis. In fact, there is a strong tendency to form agglomerates that intensifies with particle size decreases. The matrix in the liquid state favours this tendency even more, and the increase in rotation on its own is not enough to break the agglomerates. In contrast, with the matrix in the semi-solid state, the abrasion among particles and between particles and the solid $\alpha$ phase promote a more effective agglomerate breakage. Thus, two phenomena with distinct effects are responsible for particle wetting.

It is a well-known fact that, in reactive systems, the solid wetting by liquid is accompanied by extensive chemical reactions with the formation of a new compound on the interface. This is characterized by the preponderance of the wetting kinetics in relation to the thermodynamics of the process. However, the previous analysis confirms Eustathopoulos' ${ }^{15,16}$ conclusions and Zhong's ${ }^{17}$ model, in which a good wetting can only be accomplished with a high enough concentration of the reactive element in the liquid, as well as the determining factor in wetting of the reactive systems is the final interface chemistry and not the interfacial reaction intensity. For this reason, time, has no strong influence on the process, as demonstrated by the factorial experiment.

It is interesting to distinguish two concepts: rotation as a separate factor, and the stirring system, which includes the propeller blade geometry, acting along with rotation to promote the slurry flow with particle drag and shear forces. Interpreting rotation as representative of the stirring system is not an exaggerated extrapolation but is perfectly plausible. Therefore, the stirring system should be improved.

In processes with the matrix exclusively in the liquid state or exclusively in the semi-solid state, wetting and dispersion formation operate consecutively, and particle wetting is a necessary condition for particle incorporation. Once the metal wets the particles and dispersion is formed, the composite should be poured and solidified. In this stage, particles can be engulfed or pushed by the solidification front. This stage mainly affects particle distribution and material homogeneity.

The previous discussion shows that the particle wetting condition is a distinct and well characterized stage that occurs in the initial phase of the composite synthesis, during stirring in the slurry stage. Dispersion itself is produced during stirring in the 60 -second total liquid state that precedes pouring.

\section{Conclusions}

In light of this work's results and the formulated discussions, the following conclusions can be drawn:

1) The factors of greater influence on the incorporated fraction are particle size and initial added fraction, with a strong interaction of these two factors;

2) The best incorporations are obtained with all factors at the highest level;

3) The time factor, in the order of magnitude used in this experiment, does not show any significant influence on the incorporation process;

4) The stirring system exerts a significant role as a promoter of the interaction among the phases present in the semi-solid slurry, favouring particle wetting. Thus, designing stirring systems that promote more effective interactions in the semi-solid pasty state increases the incorporated fraction or particle incorporation with less particle size;

5) Particle wetting occurs in the metal semi-solid condition due to the interactions among the particles themselves and between particles and the remaining liquid phase.

\section{Acknowledgements}

The authors are grateful for Dr. Rogerio Hein's help during image acquisition. Also we would like to thank NOVELIS - Poços de Caldas/MG for the supplying the AA 356 alloy and alumina powder. 


\section{References}

1. Levi CG, Abbaschian GJ and Meharabian R. Interface interactions during fabrication of aluminum alloy alumina fiber composites. Metallurgical Transactions. 1978; 9A:697-711.

2. Ghost PG and Ray S. Effect of mixing parameters on the microstructure of compocasting $\mathrm{Al}(\mathrm{Mg})-\mathrm{Al}_{2} \mathrm{O}_{3}$ particle composite. Zeitschrift Furmetallkunde. 1990; 81(7):525-529.

3. Quingley BF, Abbaschian GJ, Wunderlin R and Mehrabian R. A method for fabrication of aluminum-alumina composites. Metallurgical Transactions. 1982; 13A:93-100.

4. Pai BC, Ramani G, Pillai RM and Satyanarayma G. Role of magnesium in cast aluminium alloy matrix composite. Journal of Material Science. 1995; 30:903-1911. http://dx.doi. org/10.1007/BF00353012

5. Mcleod AD and Gabryel CM. Kinetics of the growth of spinel, $\mathrm{MgAl}_{2} \mathrm{O}_{4}$, on alumina particulate in aluminum alloys containing magnesium. Metallurgical Transactions. 1992; 23A:12791283.

6. Naher S, Brabazon D and Looney L. Development and assessment of a new quick quench stir caster design for the production of metal matrix composites. Journal of Materials Processing Technology. 2004; 166(3):430-439. http://dx.doi. org/10.1016/j.jmatprotec.2004.09.043

7. Naher S, Brabazon D and Looney L. Simulation of the stir casting process. Journal of Materials Processing Technology. 2005; 166:430-439. http://dx.doi.org/10.1016/j. jmatprotec.2004.09.043

8. Haizhi Y. An overview of the development of Al-Si-alloy based material for engine applications. Journal of Materials Engineering and Performance. 2003; 12:288-297.
9. Jeng $\mathrm{S}$ and Chen $\mathrm{S}$. The solidification characteristics of 6061 and AA 356 aluminum alloys and their ceramic particle reinforced composites. Acta Materialia. 1997; 12:4887-4899. http://dx.doi.org/10.1016/S1359-6454(97)00189-4

10. Ranieri K and Kiyan K. Project and construction of equipment for synthesis of particulated metal matrix composite, using mechanical stir casting. In: Proceedings of the 19th International Congress of Mechanical Engineering COBEM; 2007; Brasília, Brazil. Brasília; 2007.

11. Ranieri K, Costa AFB and Kiyan C. Stratified sampling applied to estimation of the volumetric fraction of alumina in cast metal matrix composites. Practical Metallography. 2009; 8:46-62.

12. ImageJ. Image Processing and Analisys in Java. 2009. Available from: <http://rsb.info.nih.gov/ij/>.

13. Montgomery DC. Design and Analysis of Experiments. New York: John Wiley \& Sons; 2005.

14. Iligbusi GJ and Szekely J. The engulfment of particles by an electromagnetically stirred melt. Journal of Colloid and Interface Science. 1988; 123; 2:567-574. http://dx.doi. org/10.1016/0021-9797(88)90023-9

15. Eustathopoulos N. Dynamics of wetting in reactive metal ceramic systems. Acta Metallurgica. 1998; 7:2319-2327.

16. Eustathopoulos N. Progress in understanding and modeling reactive wetting of metals on ceramics. Current Opinion in Solid State Mater Science. 2005; 9:152-160. http://dx.doi. org/10.1016/j.cossms.2006.04.004

17. Zhong WM, L'esperance $G$ and Suèry $M$. Interfacial reactions in $\mathrm{Al}-\mathrm{Mg} / \mathrm{Al}_{2} \mathrm{O}_{\mathrm{p}}$ composites during fabrication and remelting. Metallurgical Material Transactions. 1995; 26A:2625-2635. http://dx.doi.org/10.1007/BF02669420 